Article

\title{
Flexible 6-in-1 Microsensor for Real-Time Microscopic Monitoring of Proton Battery
}

\author{
Chi-Yuan Lee ${ }^{1, *}$, Chia-Hung Chen ${ }^{2}$, Chin-Yuan Yang ${ }^{1}$, John-Shong Cheong ${ }^{1}$, Yun-Hsiu Chien ${ }^{1}$ and Yi-Chuan Lin ${ }^{1}$ \\ 1 Yuan Ze Fuel Cell Center, Department of Mechanical Engineering, Yuan Ze University, \\ Taoyuan 32003, Taiwan; roy6051010@gmail.com (C.-Y.Y.); johnshong1018@gmail.com (J.-S.C.); \\ s1040923@g.yzu.edu.tw (Y.-H.C.); chuan881018@gmail.com (Y.-C.L.) \\ 2 HOMYTECH Global CO., LTD., Taoyuan 33464, Taiwan; chenjahon@gmail.com \\ * Correspondence: cylee@saturn.yzu.edu.tw
}

check for updates

Citation: Lee, C.-Y.; Chen, C.-H.; Yang, C.-Y.; Cheong, J.-S.; Chien, Y.-H.; Lin, Y.-C. Flexible 6-in-1 Microsensor for Real-Time Microscopic Monitoring of Proton Battery. Membranes 2021, 11, 615. https:// doi.org/10.3390/membranes11080615

Academic Editor: Fatemeh Razmjooe

Received: 19 July 2021

Accepted: 9 August 2021

Published: 12 August 2021

Publisher's Note: MDPI stays neutral with regard to jurisdictional claims in published maps and institutional affiliations.

Copyright: (c) 2021 by the authors. Licensee MDPI, Basel, Switzerland. This article is an open access article distributed under the terms and conditions of the Creative Commons Attribution (CC BY) license (https:/ / creativecommons.org/licenses/by/ $4.0 /)$.

\begin{abstract}
According to the comparison between a proton battery and a proton exchange membrane fuel cell (PEMFC), the PEMFC requires oxygen and hydrogen for generating electricity, so a hydrogen tank is required, leading to larger volume of PEMFC. The proton battery can store hydrogen in the carbon layer, combined with the oxygen in the air to form water to generate electricity; thus, the battery cost and the space for a hydrogen tank can be reduced a lot, and it is used more extensively. As the proton battery is a new research area, multiple important physical quantities inside the proton battery should be further understood and monitored so as to enhance the performance of battery. The proton battery has the potential for practical applications, as well as water electrolysis, proton storage and discharge functions, and it can be produced without expensive metals. Therefore, in this study, we use micro-electro-mechanical systems (MEMS) technology to develop a diagnostic tool for the proton battery based on the developed microhydrogen sensor, integrated with the voltage, current, temperature, humidity and flow microsensors developed by this laboratory to complete a flexible integrated 6-in-1 microsensor, which is embedded in the proton battery to measure internal important physical parameters simultaneously so that the reaction condition in the proton battery can be mastered more accurately. In addition, the interaction of physical quantities of the proton battery are discussed so as to enhance the proton battery's performance.
\end{abstract}

Keywords: proton battery; flexible 6-in-1 microsensor; real-time microscopic monitoring

\section{Introduction}

The proton battery is a very novel research area. It was first proposed by Heidari et al. from the Royal Melbourne Institute of Technology (RMIT), Australia, in March 2018 [1]. It is rechargeable and can electrolyze water. The electrolyzed protons can be stored, and the protons can be released to combine with oxygen to generate electricity. The hydrogen storage material is activated carbon instead of expensive metals, so it is a lower cost and safe.

At present, the fuel cell technology has been used in different areas, but there are still some problems to be solved, such as size, weight and hydrogen storage problems. Folonari et al. $[2,3]$ indicated that besides a higher energy density and a more compact and simple structure, the new kind of fuel cell composed of hydride electrode and solid electrolyte could maintain the advantages of a conventional fuel cell. This kind of structure could enhance the reliability and performance of electric vehicles significantly. In terms of the most mainstream fuel cells at present, the hydrogen is stored in the hydrogen storage tank, and the hydrogen storage tank is installed onto the carrier, such as vehicles and generators. Most hydrogen storage tanks use the metal hydride technique to store hydrogen. In terms of the unitized regenerative fuel cell using a metal hydride-nitride composite electrode, the storage volume of hydrogen in the electrode measured in charging mode was $0.6 \mathrm{wt} \%$. The discharged hydrogen volume was detectable, but very low, only 
about $0.01 \mathrm{wt} \%$, and there would be safety risk [4]. Jurewicz et al. [5-7] pyrolyzed viscose fabric of liquid $\mathrm{KOH}$ electrolyte (concentration $6 \mathrm{M}$ ) to prepare an activated carbon electrode for electrochemical hydrogen storage, implemented $1.5 \mathrm{wt} \%$ reversible hydrogen storage, and studied the influence of acidity and alkalinity of electrolytes on the hydrogen storage capacity. Babel et al. [8] fabricated a highly porous carbon; the $1.89 \mathrm{wt} \%$ high hydrogen storage capacity proved that high ultramicropore and micropore volume and relatively smaller mesopore volume enhanced the hydrogen storage capacity. Bosch et al. [9] enlarged the surface area and improved the material. As the nano-structure hydrogen storage characteristic of carbon was known, the feasibility of rechargeable proton battery with a high energy density and high hydrogen storage capacity could be increased. The proton battery is a very novel research area, and there are many immature prototypes [10-13]; therefore, it is a topic worthy of exploration.

The proton battery design of Andrews et al. [14] used a solid electrode made of a metal alloy to store hydrogen. The protons escape from the membrane, and the electrons combine with metal in the external circuit to form hydride.

Guterl and Fang $[15,16]$ found in the highly ordered porous carbon material that the hydrogen storage capacity was linearly related to the volume of the ultramicropore. According to the document [17-28], it is difficult to measure multiple important physical parameters inside the proton battery accurately, and the multiple important physical parameters (e.g., hydrogen, voltage, current, temperature, humidity and flow) are correlated with each other; all of them have a critical effect on the performance of the proton battery. However, the external measurement of the proton battery is the only way at the moment to know the overall output performance, and the authentic information inside the proton battery cannot be known accurately and instantly. The internal diagnosis of the proton battery is a valuable research field. In this study, we use micro-electro-mechanical systems (MEMS) technology to develop a flexible integrated microsensor embedded into the proton battery to provide valuable data.

\section{Process of Flexible 6-in-1 Microsensor}

This study used MEMS technology to integrate six sensing functions, including temperature, voltage, current, flow, humidity and hydrogen. The process of the flexible 6-in-1 microsensor is shown in Figure 1.

(a)

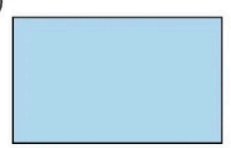

(b)

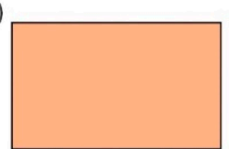

(c)

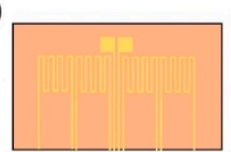

(d)

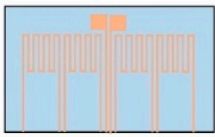

(e)

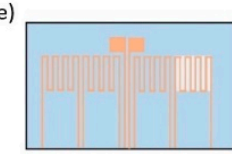

(f)

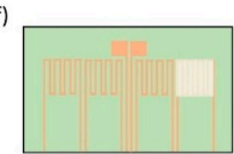

(g)

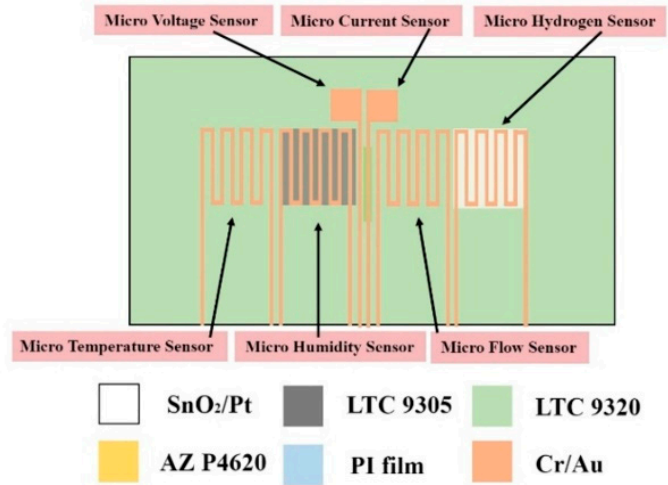

Figure 1. The process diagram of the flexible 6-in-1 microsensor.

(a) First, the PI film is cleaned with acetone and methanol organic solutions, respectively. The residual methanol is removed by DI water, and the surface dust and residual oil and fat are removed so as to enhance the adhesive ability of thin film metal.

(b) The $\mathrm{Cr}$ is evaporated by an E-beam evaporator as the adhesion layer of $\mathrm{Au}$ and PI film, the adhesiveness of $\mathrm{Au}$ and PI film is increased, and the deposition of $1000 \AA$ thick $\mathrm{Au}$ is completed at a deposition rate of $0.1 \AA / \mathrm{s}$. 
(c) The AZ P4620 (positive photoresist) is spin coated, and the electrode pattern of the microsensor is defined by exposure and development.

(d) The Au is etched by Au etching solution (Type-TFA), and the Cr is etched by Cr etching solution (Cr-7T). The photoresist as an etching mask is removed by Remove 1165 .

(e) The AZ P4620 is spin coated again as the mask for evaporation, and the microsensor pattern is defined by the exposure, and then the required pattern is developed by developer.

(f) The $\mathrm{SnO}_{2}$ is evaporated on the surface where the pattern has been defined as the gas sensing layer, and the $\mathrm{Pt}$ is evaporated as the catalyst layer.

(g) The sample is put in the $80^{\circ} \mathrm{C}$ photoresist remover (Remove 1165) and kept still for about 20 min The photoresist mask is lifted off by using lift-off method, and then the sample is cleaned with acetone and methanol.

(h) Finally, the LTC 9320 (negative photoresist) is spin coated on the flexible 6-in-1 microsensor to complete the protection layer and fabrication. Figures 2 and 3 are the optical micrograph and stereogram of the flexible 6-in-1 microsensor, respectively.

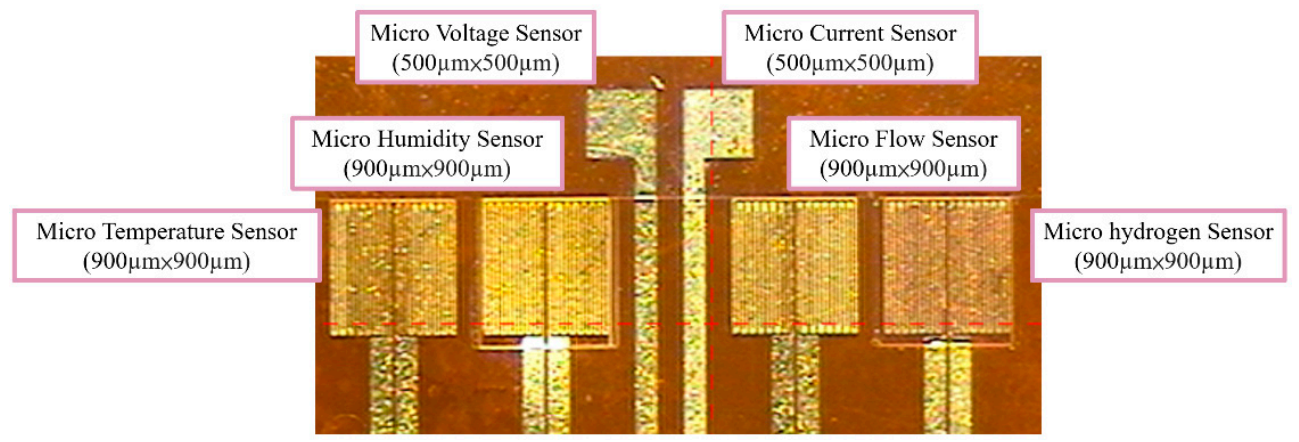

Figure 2. The optical micrograph of the flexible 6-in-1 microsensor.

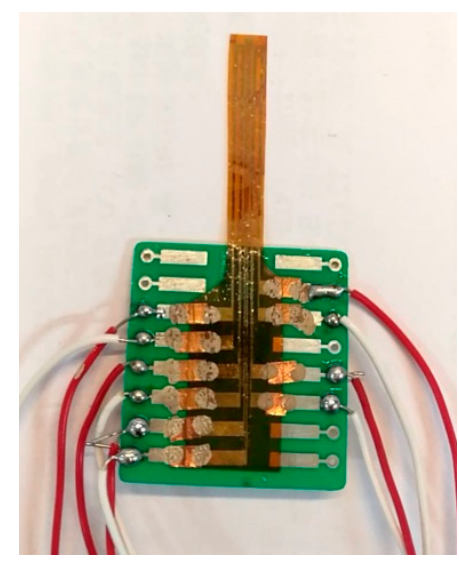

Figure 3. Stereogram of the flexible 6-in-1 microsensor.

\section{Correction of Flexible 6-in-1 Microsensor}

The micro voltage and current sensors directly export the voltage and current from the proton battery for detection, additional correction is unnecessary. The correction of micro temperature, humidity, flow and hydrogen sensors is described below.

\subsection{Temperature Distribution inside Water Electrolyzer}

The flexible 6-in-1 microsensor and the thermometer of BM-525 BRYMEN digital multimeter are put in a DENG YNG DS45 Drying Oven. After the reference control temperature is set up and stabilized, the resistance value of the micro temperature sensor is extracted. In the working temperature range, the resistance value is extracted at intervals of $10^{\circ} \mathrm{C}$, and the micro temperature sensor is corrected three times. The correction curve of 
two micro temperature sensors is measured. The curve approximates the linear variation, as shown in Figure 4.

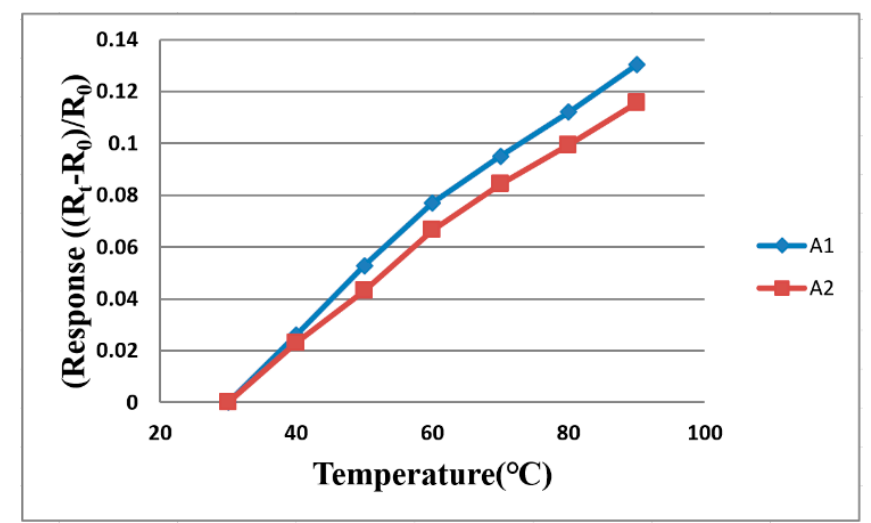

Figure 4. The correction curve of two micro temperature sensors.

\subsection{Humidity Correction of Flexible 6-in-1 Microsensor}

For humidity correction, the constant temperature and humidity testing machine is used as environmental criteria from relative humidity $40 \%$ to $100 \%$, and the temperatures $\left(30^{\circ} \mathrm{C}\right.$ and $\left.70^{\circ} \mathrm{C}\right)$ are fixed in operating condition. Each time when the relative humidity recording point is increased, the heater on the micro humidity sensor is heated to evaporate the residual moisture at the previous recording point. Each time after $120 \mathrm{~min}$ of stabilization, the NI PXI 2575 data acquisition unit is used to extract the resistance value of the micro humidity sensor instantly, so as to obtain the correction curve. Figure 5 shows the correction curve of two micro humidity sensors. The higher the temperature is, the larger is the humidity variation.

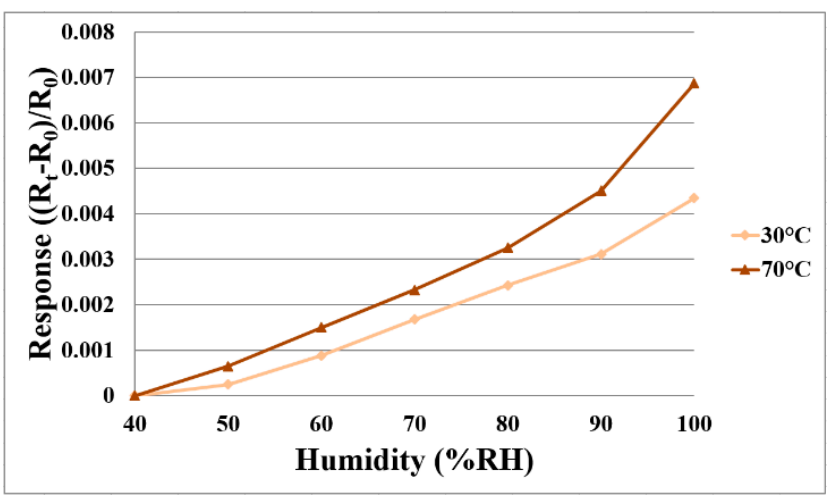

Figure 5. The correction curve of two micro humidity sensors.

\subsection{Flow Correction of Flexible 6-in-1 Microsensor}

As the proton battery is supplied with gases and water during charging and discharging, it is necessary to correct the water flow. The flexible 6-in- 1 microsensor is embedded in the proton battery, the battery testing machine supplies gases $\left(\mathrm{H}_{2}\right.$ and $\left.\mathrm{O}_{2}\right)$ as the source of flow. The power supply is connected to the signal pin of the micro flow sensor, and the anode is connected to BM-525 BRYMEN digital multimeter in a series to measure the current variation. The power supply supplies a constant voltage to the microflow sensor to generate a stable heat. First, the reference current value at $0 \mathrm{~mL} / \mathrm{min}$ is measured. The hydrogen flow correcting range is 100 to $300 \mathrm{~mL} / \mathrm{min}$, and it is measured at intervals of $50 \mathrm{~mL} / \mathrm{min}$. The oxygen flow correcting range is 400 to $600 \mathrm{~mL} / \mathrm{min}$, and it is measured at intervals of $50 \mathrm{~mL} / \mathrm{min}$. The measured correction curve of two microflow sensors is shown in Figure 6a,b. 

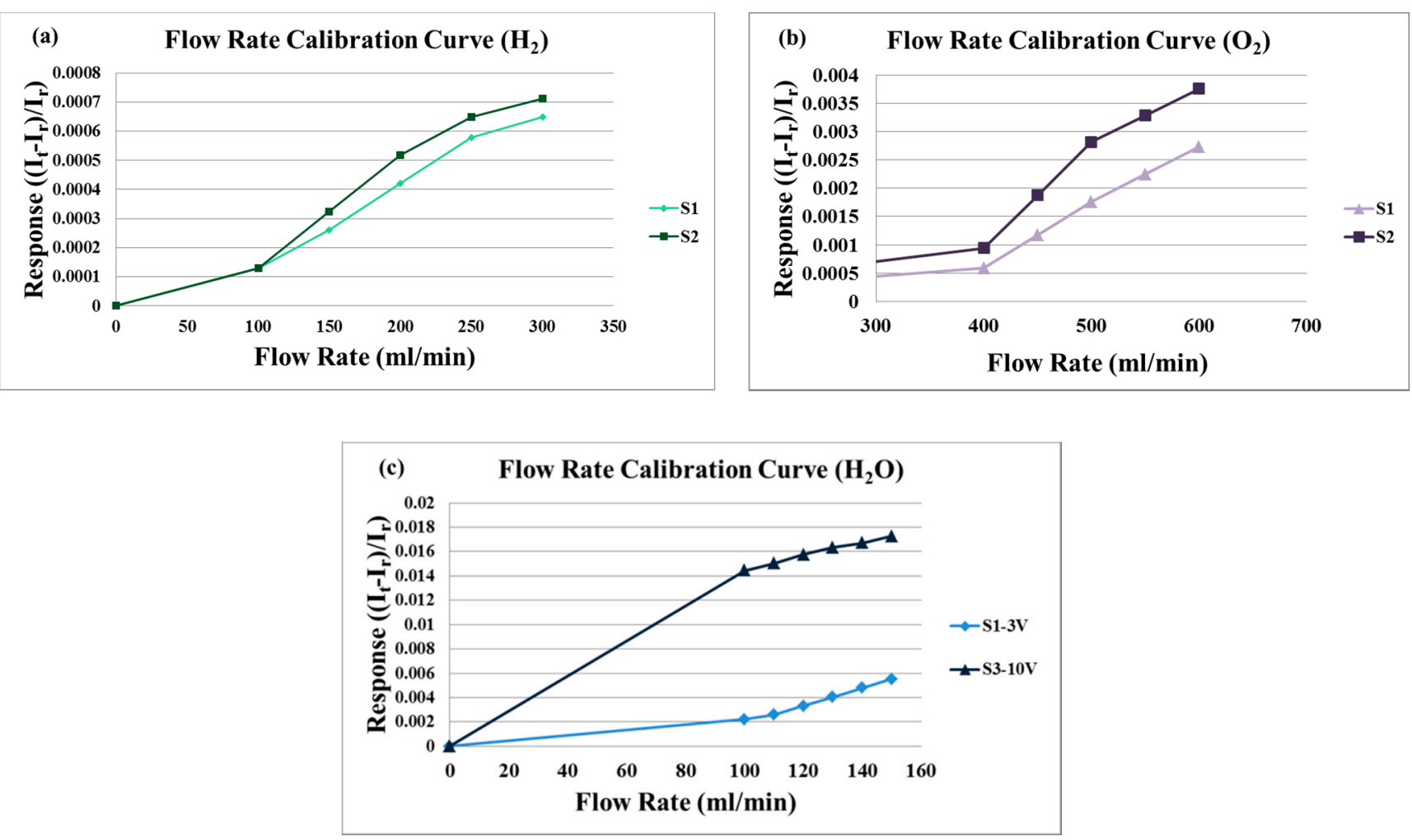

Figure 6. (a) The correction curve of two micro flow sensors $\left(\mathrm{H}_{2}\right)$. (b) The correction curve of two micro flow sensors $\left(\mathrm{O}_{2}\right)$. (c) The correction curve of two micro flow sensors $\left(\mathrm{H}_{2} \mathrm{O}\right)$.

For liquid $\left(\mathrm{H}_{2} \mathrm{O}\right)$ flow correction, the LEADFLUID BT100S-1 speed adjusting peristaltic pump provides a steady flow. The flow correction range is 100 to $150 \mathrm{~mL} / \mathrm{min}$, measured at intervals of $10 \mathrm{~mL} / \mathrm{min}$. The correction curve of two micro flow sensors is shown in Figure 6c.

\subsection{Hydrogen Correction of Flexible 6-in-1 Microsensor}

The flexible micro hydrogen sensor performance testing aims to know the sensing condition and efficiency of the micro hydrogen sensor and to determine the operation and process optimization parameters in order to manufacture a microhydrogen sensor operated at low temperatures. Figure 7 shows the optical micrograph of $\mathrm{SnO}_{2}$ in different thicknesses $(50,100,150 \mathrm{~nm})$ (the uppermost layer is coated with $2.5 \mathrm{~nm}$ thick Pt as catalyst layer). The micro hydrogen sensor is tested and corrected by a fuel cell testing machine, as shown in Figure 8. The fuel cell testing machine can supply different gases, set up the gas flow and heat gases. Therefore, the microhydrogen sensor is embedded in the proton battery runner plate, and the flow channel of proton battery is used as a closed chamber for the test. First, the micro hydrogen sensor is connected to NI PXI-1033 of a computer to detect the resistance change, supplied with oxygen at a constant temperature and constant flow so that the surface of micro hydrogen sensor can adsorb oxygen ions $\left(\mathrm{O}^{-}\right)$. Afterwards, the hydrogen at a constant temperature and constant flow is supplied, and the $\mathrm{O}^{-}$is carried away from the surface of micro hydrogen sensor so that the micro hydrogen sensor resistance decreases. The hydrogen is detected using the resistance difference among different gases. 


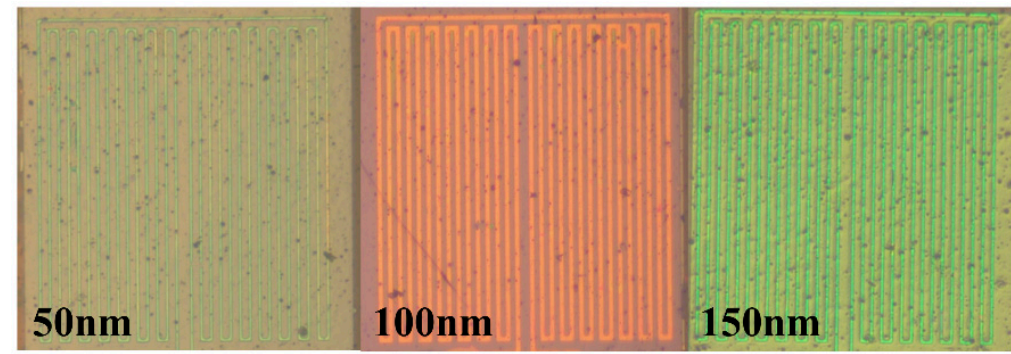

Figure 7. Optical micrograph of evaporated $\mathrm{SnO}_{2}$ in different thicknesses $(50,100,150 \mathrm{~nm})(2.5 \mathrm{~nm}$ thick $\mathrm{Pt}$ is evaporated on the uppermost layer as catalyst layer).

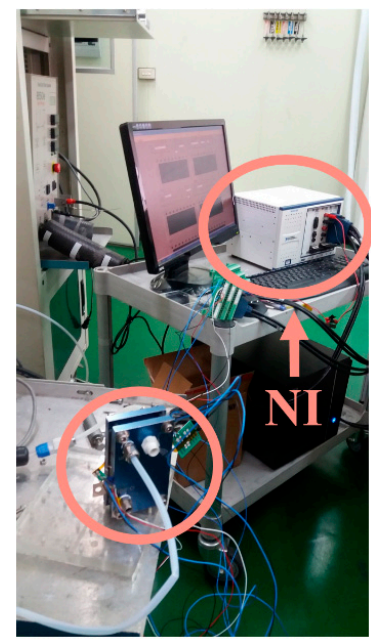

Figure 8. Test and correction of micro hydrogen sensor.

\section{Internal Real-Time Microscopic Diagnosis of Proton Battery}

The flexible 6-in-1 microsensor can be embedded in the proton battery before the experiment. The activated carbon powder is put in the hydrogen-side flow channel before assembly. After assembly, the sulfuric acid is added to the hydrogen side through the upstream inlet. The flexible 6-in-1 microsensor is used for internal data and proton battery analysis, real-time microscopic monitoring of changes in temperature, voltage, current, flow and humidity and detecting the generation of hydrogen.

The fuel cell testing equipment is used for the discharge test. The pure oxygen is added to the oxygen side at room temperature $\left(25^{\circ} \mathrm{C}\right)$, the flow is set as $500 \mathrm{~mL} / \mathrm{min}$, as shown in Figure 9.

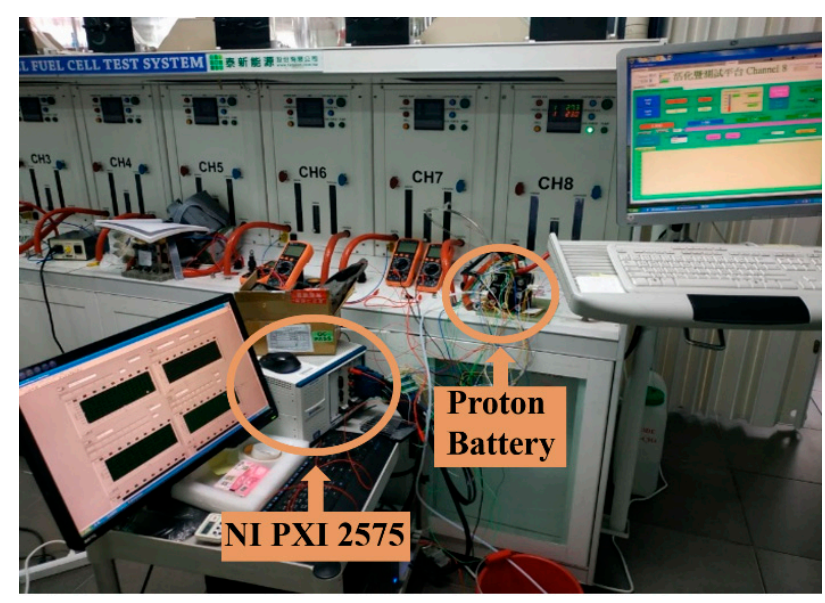

Figure 9. Discharge test. 


\subsection{Internal Runner Design for Proton Battery}

The main purpose of runner design is to uniformly distribute fluid over the proton exchange membrane. The runner design of the bipolar plate is related to the proton battery efficiency, so the area, width and depth of the runner can influence the reaction of the proton battery.

The common designs of runner plate include mesh flow field, parallel flow field, single serpentine flow field and double serpentine flow field. The selected runner design is a serpentine nonparallel flow field (area is $25 \mathrm{~cm}^{2}$ ), as shown in Figure 10. Table 1 shows the bipolar runner plate specification.

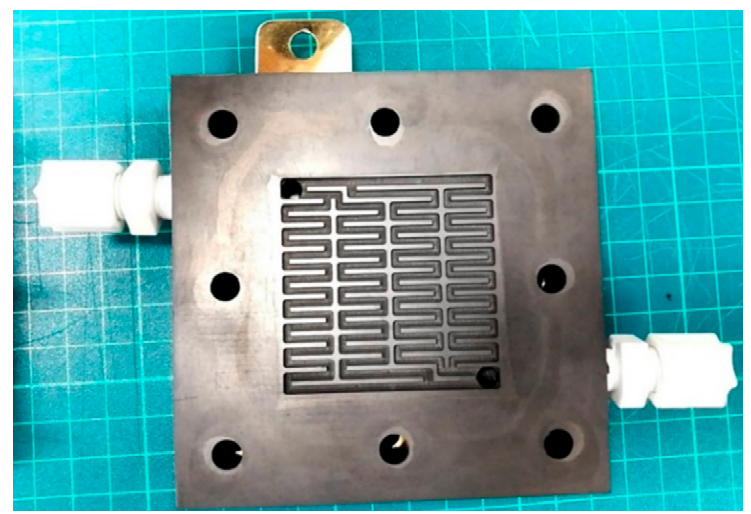

Figure 10. Serpentine nonparallel runner plate1.

Table 1. Specification of the bipolar runner plate.

\begin{tabular}{cc}
\hline Characteristic & Specification \\
\hline Thickness of BP $(\mathrm{mm})$ & 20 \\
\hline Channel type & Multi-serpentine flow field \\
\hline Channel depth $(\mathrm{mm})$ & 1.5 \\
\hline Channel width $(\mathrm{mm})$ & 1.5 \\
\hline Rib width $(\mathrm{mm})$ & 1 \\
\hline
\end{tabular}

\subsection{Proton Battery Assembly Method}

Assembly process:

(a) Remove dirt with ethanol and DI water;

(b) Cover the bolt with thermal shrinkage agent to prevent short circuit of battery;

(c) Fix four bolts into the holes in the end plate for positioning and subsequent battery assembly;

(d) Fix the silicon spacer between the end plate and collector plate by bolt so that the silicon spacer can be pressed uniformly when fixing the battery;

(e) Place the collector plate on the silicon resin washer using bolt;

(f) Place the bipolar plate with runner up above the collector plate;

(g) Place the MEA above the bipolar plate;

(h) Place another bipolar plate on the MEA, the runner faces the MEA;

(i) Place on another collector plate;

(j) Place on the silicone rubber gasket;

(k) Place on another end plate;

(1) Diagonally fix the nut to $10 \mathrm{kgf} \cdot \mathrm{cm}$ with a torque wrench. The torque of each nut must be the same and increased by $5 \mathrm{kgf} \cdot \mathrm{cm}$ till $25 \mathrm{kgf} \cdot \mathrm{cm}$, so as to prevent the bipolar plate and collector plate from deforming or breaking due to nonuniform stress during tightening, the clamping pressure too small will also cause the gas diffusion layer unable to contact the graphite plate and make the battery unable to charge normally; 
(m) The proton battery assembly is completed, as shown in Figure 11.

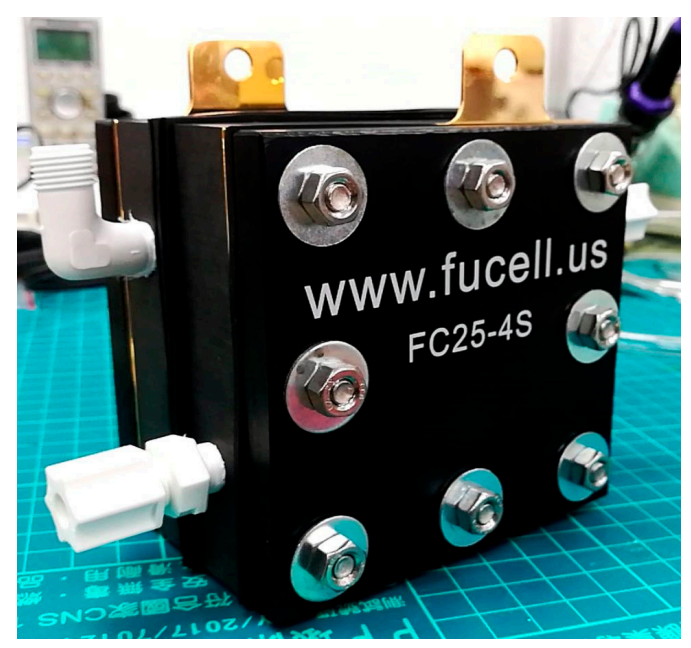

Figure 11. The proton battery.

\subsection{Calibration of Flexible Iintergrated 6-in-1 Microsensor and Proton Battery}

The constant current is adjusted to $40 \mathrm{~mA}$ according to the performance of the proton battery, and the changes in voltage, current and power are observed, as shown in Figures 12 and 13. The discharging efficiency of the proton battery is about $0.37 \mathrm{wt} \%$, and the volume of released hydrogen is only half of the volume of the absorbed hydrogen. This may be related to the catalyst layer of the proton exchange membrane.

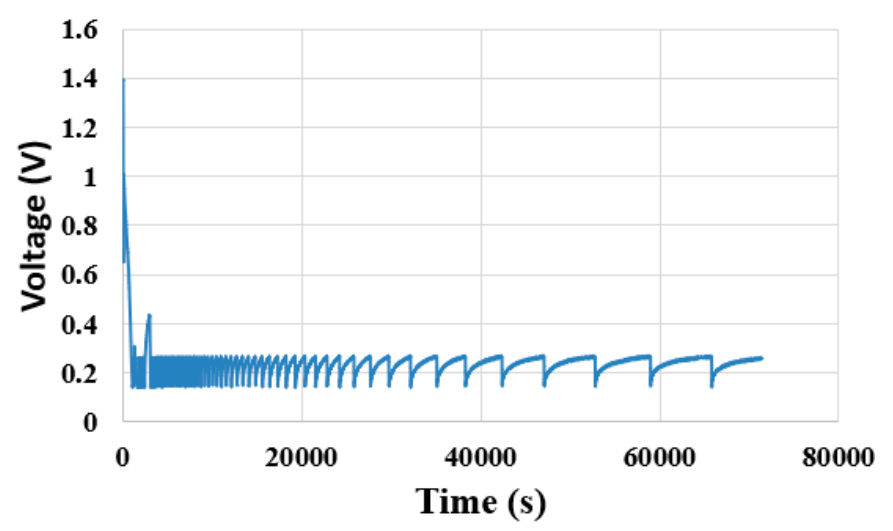

Figure 12. Voltage changes during the proton battery discharge.

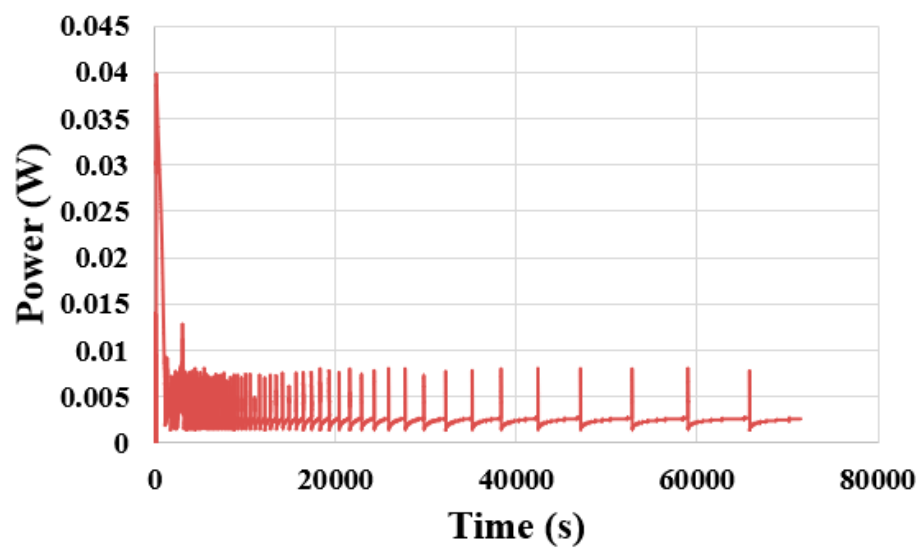

Figure 13. Power output during the proton battery discharge. 


\subsection{Temperature Distribution inside Proton Battery}

The discharge process of the proton battery is performed at room temperature $\left(25^{\circ} \mathrm{C}\right)$, and the temperature distribution is shown in Figures 14 and 15. The downstream oxygen side temperature is higher than the upstream temperature. Due to the reaction, the upstream temperature of the hydrogen side will rise slightly, and then the temperature is stabilized at about $26^{\circ} \mathrm{C}$ as the release efficiency decreases.

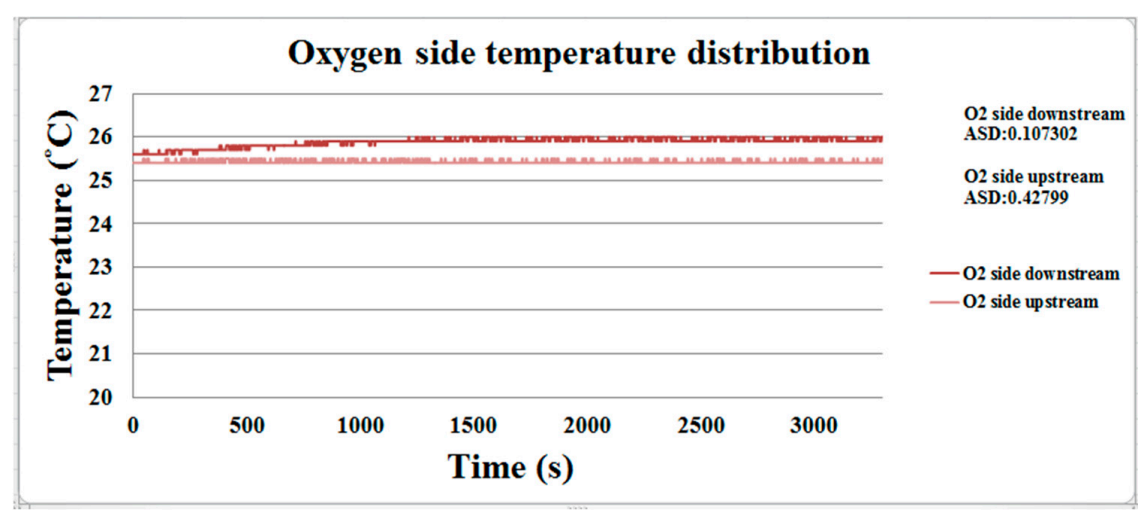

Figure 14. The oxygen side's temperature distribution during the proton battery discharge.

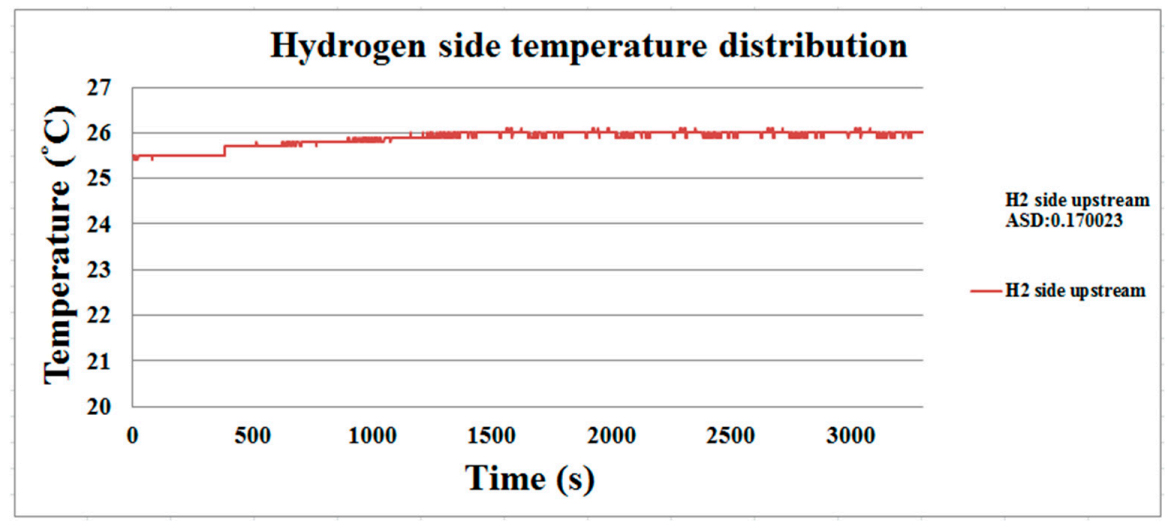

Figure 15. The hydrogen side's temperature distribution during the proton battery discharge.

\subsection{Flow Distribution inside Proton Battery}

The flow velocity set in the fuel cell testing equipment is $500 \mathrm{~mL} / \mathrm{min}$, as shown in Figure 16. The upstream flow is higher than the downstream flow, which resulted from the power generation reaction and gas diffusion layer. In the initial stage, the downstream flow velocity is lower, meaning the earlier the power generation reaction is, the higher is the gas flow, and then when the reaction slows down, the flow velocity becomes stable.

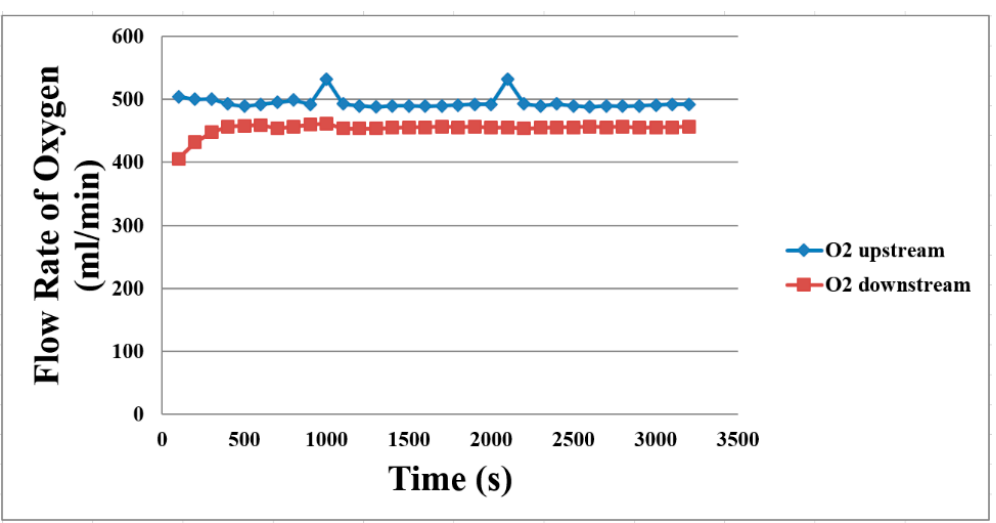

Figure 16. The oxygen side's flow distribution during the proton battery discharge. 


\subsection{Humidity Distribution inside Proton Battery}

The fuel cell testing equipment supplies wet oxygen so that the proton exchange membrane has a good working environment and the measured humidity is higher. As shown in Figure 17, the oxygen side increases slowly from lower humidity, and the downstream humidity is higher. This is related to the combination of hydrogen and oxygen. However, as the electricity generation decreases, the reaction is very slight, and the upstream and downstream humidities are overlapped in the late stage.

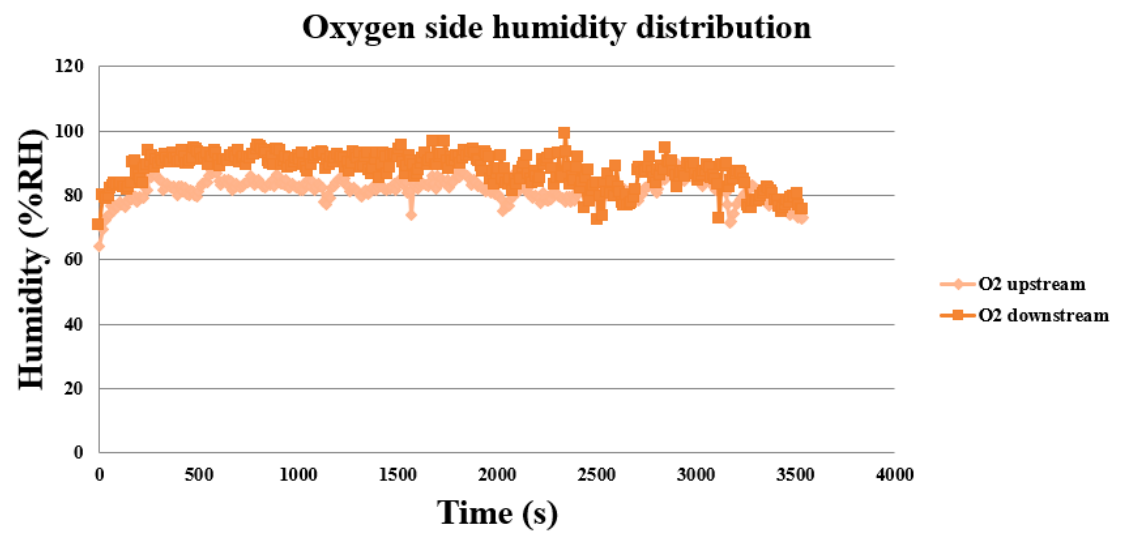

Figure 17. The oxygen side's humidity distribution during the proton battery discharge.

\subsection{Hydrogen Distribution inside Proton Battery}

The resistance changes measured by the micro hydrogen sensor on the hydrogen side are shown in Figure 18. Since the electrical group of the hydrogen sensor is very small, the ohmic change is not obvious, so it can also be known that the micro hydrogen sensor needs oxygen for restoring the conditions for detecting hydrogen. The micro hydrogen sensor cannot detect hydrogen very well due to the hydrogen side is sealed.

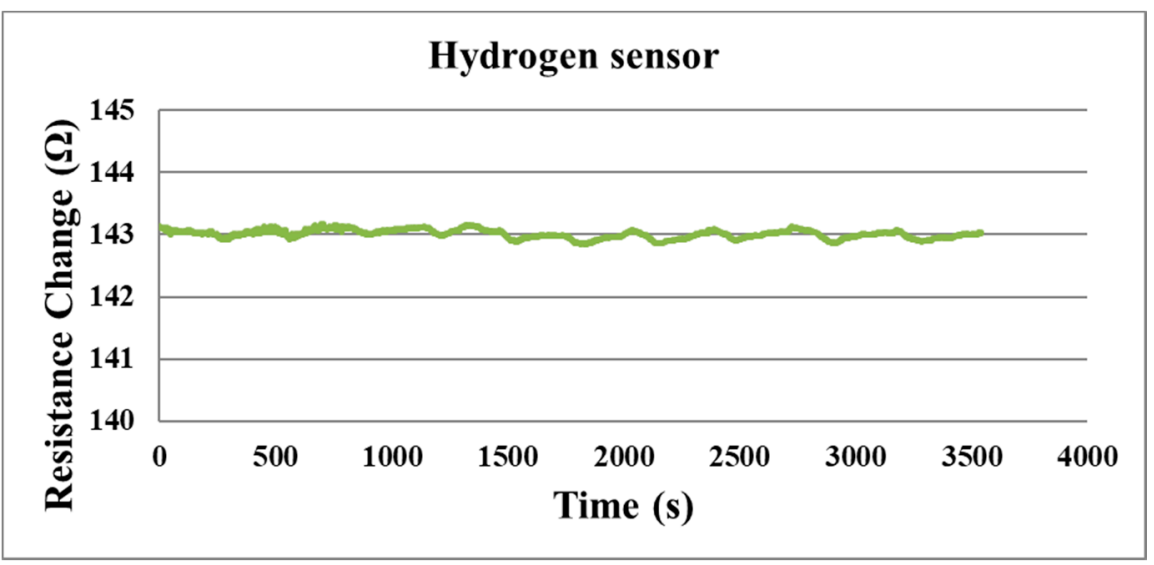

Figure 18. The hydrogen side's hydrogen detection.

\subsection{Discussion}

The operating temperature was set to $25^{\circ} \mathrm{C}$, and the microsensor was placed in different places in the oxygen side and the hydrogen side to observe the temperature distribution in the proton battery. From the oxygen side, it can be found that the water inlet is upstream, so the upstream temperature is lower, and the downstream temperature higher is because the temperature will increase after the reaction. Since sulfuric acid does not flow on the hydrogen side, the battery will tend to heat up gradually. On the oxygen side, the flow rate of water distribution upstream has a larger flow rate than downstream due to the water electrolysis inside the proton battery, and GDL could lead to resistance of the water flow. On the hydrogen side, we only need to measure the hydrogen flow rate, 
but the measured value is very strange. It is because the change of current of the micro flow sensor is too small and exceeds the limit of the measuring equipment we use. On the other hand, the flow rate of hydrogen at the hydrogen side is incoherent and makes the heated micro flow sensor unable to measure accurately. The measurement of the miniature hydrogen sensor cannot work normally in a closed space. In addition, the micro flow sensor cannot be measured in a non-constant current state based on the limitation of the measuring device, so the measurement results of these two physical quantities are not considered successful.

\section{Conclusions}

In this study, the micro temperature, voltage, current, flow, humidity and hydrogen sensors were successfully integrated onto a $50 \mu \mathrm{m}$ thick PI film using MEMS technology. This flexible 6-in-1 microsensor has six sensing structures. It is characterized by a small thickness, small area, high sensitivity and arbitrary placement. The flexible 6-in-1 microsensor is embedded in the runner plates of the oxygen side and hydrogen side of the proton battery. The proton battery sealing condition was not influenced. In the operation of the proton battery, the changes in the temperature, voltage, current, flow, humidity and hydrogen of the proton battery were measured successfully. During the discharge of the proton battery, the power output of only $0.37 \mathrm{wt} \%$ is obtained. The amount of hydrogen released is only half of the amount of hydrogen absorbed, which may be related to the catalytic layer of the proton exchange membrane, which is more suitable for a water electrolysis reaction but not suitable for a reverse reaction. Future research should be aimed at miniaturizing the microsensor, which can reduce the effect of the microsensor on the proton battery. In the proton battery part, the hydrogen storage-activated carbon can move to the outside of the battery, and the activated carbon and sulfuric acid should be circulated in the battery through the pump, which can remove the restriction of the proton battery on the amount of hydrogen storage material. Then, find a better catalyst layer of the proton exchange membrane, which can provide better performance when in the charge mode or discharge mode.

Author Contributions: The work presented here was carried out in collaboration between all authors. C.-Y.L. and C.-H.C. conceived, designed, and discussed this study C.-Y.Y., J.-S.C., Y.-H.C. and Y.-C.L. performed the experiments and analyzed the data. All authors have contributed, reviewed, and improved the manuscript. All authors have read and agreed to the published version of the manuscript.

Funding: The authors are grateful to the Ministry of Science and Technology of R.O.C. through the grant MOST 108-2221-E-155-049-MY2, 109-2622-E-155-008, 109-2622-E-155-013, 110-2221-E-155-034 and 110-2221-E-155-061.

Acknowledgments: The authors would also like to thank the HOMY Technology, YZU Fuel Cell Center and NENS Common Lab, for providing access to their research facilities.

Conflicts of Interest: The authors declare no conflict of interest.

\section{References}

1. Heidari, S.; Mohammadi, S.S.; Oberoi, A.S.; Andrews, J. Technical feasibility of a proton battery with an activated carbon electrode. Int. J. Hydrogen Energy 2018, 43, 6197-6209. [CrossRef]

2. Folonari, C.; Iemmi, G.; Manfredi, F.; Rolle, A. Metal hydride fuel cells: A feasibility study and perspectives for vehicular applications. J. Less Common Met. 1980, 74, 371-378. [CrossRef]

3. Condon, J.B.; Schober, T. Proton conductors and metal hydrides. Solid State Ion. 1995, 77, 299-304. [CrossRef]

4. Selembo, P.A.; Merrill, M.D.; Logan, B.E. Hydrogen production with nickel powder cathode catalysts in microbial electrolysis cells. Int. J. Hydrogen Energy 2010, 35, 428-437. [CrossRef]

5. Jurewicz, K.; Frackowiak, E.; Béguin, F. Enhancement of reversible hydrogen capacity into activated carbon through water electrolysis. Electrochem. Solid State Lett. 2001, 4, A27-A29. [CrossRef]

6. Jurewicz, K.; Frackowiak, E.; Béguin, F. Electrochemical storage of hydrogen in activated carbons. Fuel Process Technol. 2002, 77-78, 415-421. [CrossRef] 
7. Jurewicz, K.; Frackowiak, E.; Béguin, F. Towards the mechanism of electrochemical hydrogen storage in nanostructured carbon materials. Appl. Phys. A 2004, 78, 981-987. [CrossRef]

8. Babel, K.; Jurewicz, K. KOH activated lignin based nanostructured carbon exhibiting high hydrogen electrosorption. Carbon 2008, 46, 1948-1956. [CrossRef]

9. Bosch, M.; Zhou, H.C. Porous carbons for hydrogen storage. In Nanostructured Materials for Next-Generation Energy Storage and Conversion; Springer: Berlin/Heidelberg, Germany, 2017; pp. 171-202.

10. Han, G.; Kwon, Y.; Kim, J.B.; Lee, S.; Bae, J.; Cho, E.; Lee, B.J.; Cho, S.; Park, J. Development of a high-energy-density portable/mobile hydrogen energy storage system incorporating an electrolyzer, a metal hydride and a fuel cell. Appl. Energy 2020, 259, 114175-114187. [CrossRef]

11. Doddathimmaiah, A.; Andrews, J. Theory, modelling and performance measurement of unitised regenerative fuel cells. Int. J. Hydrogen Energy 2009, 34, 8157-8170. [CrossRef]

12. Wang, Y.; Leung, D.Y.C.; Xuana, J.; Wang, H. A review on unitized regenerative fuel cell technologies, part-A: Unitized regenerative proton exchange membrane fuel cells. Renew. Sustain. Energy Rev. 2016, 65, 961-977. [CrossRef]

13. Paul, B.; Andrews, J. PEM unitised reversible/regenerative hydrogen fuel cell systems: State of the art and technical challenges. Renew. Sustain. Energy Rev. 2017, 79, 585-599. [CrossRef]

14. Andrews, J.; Seif, S. Mohammadi Towards a 'proton flow battery': Investigation of a reversible PEM fuel cell with integrated metal-hydride hydrogen storage. Int. J. Hydrogen Energy 2014, 39, 1740-1751. [CrossRef]

15. Guterl, C.V.; Frackowiak, E.; Jurewicz, K.; Friebe, M.; Parmentier, J.; Béguin, F. Electrochemical energy storage in ordered porous carbon materials. Carbon 2005, 43, 1293-1302. [CrossRef]

16. Fang, B.; Zhou, H.; Honma, I. Ordered porous carbon with tailored pore size for electrochemical hydrogen storage application. J. Phys. Chem. B 2006, 110, 4875-4880. [CrossRef]

17. Ou, K.; Yuana, W.W.; Choi, M.; Yang, S.; Kim, Y.B. Performance increase for an open-cathode PEM fuel cell with humidity and temperature control. Electrochim. Acta 2018, 42, 432-446. [CrossRef]

18. Yang, K.; Yang, Q.; Zhu, X.; Wang, H.; Zhu, T.; Liu, J. A molecular dynamics simulation on the static calibration test of a revised thin-film thermopile heat-flux sensor. Measurement 2020, 150, 107039. [CrossRef]

19. Ko, D.; Doh, S.; Park, H.S.; Kim, M.H. Investigation of the effect of operating pressure on the performance of proton exchange membrane fuel cell: In the aspect of water distribution. Renew. Energy 2018, 115, 896-907. [CrossRef]

20. Ahmadi, N.; Kõrgesaar, M. Analytical approach to investigate the effect of gas channel draft angle on the performance of PEMFC and species distribution. Int. J. Heat Mass Transf. 2020, 152, 119529-119545. [CrossRef]

21. Zhang, G.; Jiao, K. Three-dimensional multi-phase simulation of PEMFC at high current density utilizing Eulerian-Eulerian model and two-fluid model. Energy Convers. Manag. 2018, 176, 409-421. [CrossRef]

22. Futter, G.A.; Latz, A.; Jahnke, T. Physical modeling of chemical membrane degradation in polymer electrolyte membrane fuel cells: Influence of pressure, relative humidity and cell voltage. J. Power Sources 2019, 410-411, 78-90. [CrossRef]

23. Hiramitsu, Y.; Kobayashi, K.; Hori, M. Enhanced water management via the optimization of cathode microporous layer using 3D graphene frameworks for direct methanol fuel cell. J. Power Sources 2020, 451, 227800-227809.

24. Carcadea, E.; Varlam, M.; Ismail, M.; Ingham, D.B.; Marinoiu, A.; Raceanu, M.; Jianu, C.; Patularu, L.; Ebrasua, D.I. PEM fuel cell performance improvement through numerical optimization of the parameters of the porous layers. Int. J. Hydrogen Energy 2020, 45, 7968-7980. [CrossRef]

25. Vincent, I.; Lee, E.C.; Kim, H.M. Solutions to the water flooding problem for unitized regenerative fuel cells: Status and perspectives. RSC Adv. 2020, 10, 16844-16860. [CrossRef]

26. Rosli, R.E.; Sulong, A.B.; Daud, W.R.W.; Zulkifley, M.A.; Rosli, M.I.; Majlan, E.H.; Haque, M.A.; Radzuan, N.A.M. Experimental investigation on the voltage uniformity for a PEMFC stack with different dynamic loading strategies. Int. J. Hydrogen Energy 2020, $45,26490-26500$.

27. Falagüerra, T.; Muñoz, P.; Correa, G. Analysis of the cathode side of a PEMFC varying design parameters to optimize current distribution and power density. J. Electroanal. Chem. 2021, 880, 114820-114831. [CrossRef]

28. Bayrak, Z.U.; Kaya, U.; Oksuztepe, E. Investigation of PEMFC performance for cruising hybrid powered fixed-wing electric UAV in different temperatures. Int. J. Hydrogen Energy 2020, 45, 7036-7045. [CrossRef] 